\title{
Avaliação do uso da primeira Via Calma em Curitiba/PR para ciclomobilidade
}

\section{Evaluation of the first Via Calma use in Curitiba-PR to cyclomobility}

Ingrid Steil Ferraz ${ }^{[0]}$, Nivaldo Simões Gomes ${ }^{[0]}$, Fabio Fernando Kobs ${ }^{[a, b]}$, Maclovia Correa da Silva ${ }^{[0]}$, Eloy Fassi Casagrande Júnior ${ }^{[a]}$

\author{
[a] Universidade Tecnológica Federal do Paraná (UTFPR), Curitiba, PR, Brasil \\ [b] Universidade do Estado de Santa Catarina (UDESC), São Bento do Sul, SC, Brasil
}

\section{Resumo}

O tema deste artigo é a promoção da ciclomobilidade que aconteceu em Curitiba, no Estado do Paraná, com a implantação da primeira Via Calma da cidade, na Avenida Sete de Setembro. 0 problema norteador da pesquisa é o crescimento das cidades e os conflitos por espaços de qualidade para pedestres e para outros modos leves de deslocamento, como a bicicleta. 0 objetivo da pesquisa foi levantar os pontos de vista de usuários, concernentes ao atendimento da função dos diferentes tipos de modais da Via Calma e sua importância para a mobilidade na cidade. Os procedimentos metodológicos compreenderam uma avaliação com usuários que responderam a um questionário, com o uso da técnica de preferência declarada. Foram 90 respondentes captados por meio das redes sociais da internet. Os resultados do universo pesquisado apontaram que 29\% já usavam a bicicleta como meio de transporte e que, dentre aqueles que não a utilizavam, $52 \%$ demonstraram o interesse em trocar o meio de transporte atualmente utilizado pela bicicleta. A relevância dos resultados da enquete indicou o lado positivo da iniciativa municipal de criar um espaço específico para a circulação de bicicletas. No entanto, os respondentes, que se apropriaram da ideia, manifestaram insegurança ao circular com os carros ao lado deles. Considerou-se válida essa primeira iniciativa da municipalidade para estimular a ciclomobilidade. Assim, a tendência é a apropriação da Via Calma por novos ciclistas.

Palavras-chave: Ciclomobilidade. Curitiba/PR. Via Calma. Faixa compartilhada. Preferência declarada.

\section{Abstract}

The theme of this article is to promote the cycle mobility that happened in the city of Curitiba-PR, with the implementation of the first Via Calma of the city on Sete de Setembro Avenue, downtown. The guiding research problem is the growth of cities and conflicts of quality spaces for walking and other light modes of travel, such as cycling. The objective of this research was to gather the views of users, in different modes of Via Calma, concerning the service function of the same and its importance to mobility in the city. The methodological

ISF é mestre em Tecnologia, bacharel em Administração, e-mail: ingrid_steilferraz@hotmail.com NSG é doutor em Tecnologia, bacharel em Desenho Industrial, e-mail: nivaldo_gomes@yahoo.com.br FFK é doutor em Tecnologia, bacharel em Ciências da Computação, e-mail: fabiofk@gmail.com MCS é doutora em Arquitetura e Urbanismo, graduada em Ciências Econômicas e Letras, e-mail: macloviasilva@utfpr.edu.br EFCJ é doutor em Engenharia de Recursos Minerais e Meio Ambiente, bacharel em Desenho Industrial, e-mail: eloy.casagrande@gmail.com 
procedures include an evaluation with users who answered a questionnaire, using the stated preference survey technique. There were 90 respondents, obtained using social networks on Internet. The results of the group studied showed that 29\% already use the bicycle as a form of transport and among those who do not use, 52\%, have shown that there is interest in exchanging the form of transportation currently used for bicycle. The relevance of the survey results indicated the positive side of the municipal initiative to create a specific space for bicycle traffic. On the other hand, respondents, who have appropriated the ideas, expressed insecurity when cycling with the cars next to them. It was considered valid this first initiative of the municipality to stimulate cycle mobility and the tendency is the appropriation of the Via Calma for new cyclists.

Keywords: Cycle mobility. Curitiba/PR. Calm route. Shared lane. Stated preference.

\section{Introdução}

A mobilidade urbana é um componente imprescindível à saúde das cidades e deve ser pensada para as pessoas, e não somente para os veículos motorizados. Quando desenhados por arquitetos, urbanistas, engenheiros e técnicos, os centros urbanos ofereciam espaços para pedestres, carroças, animais e veículos. A densidade populacional e construtiva, na medida em que foi aumentando, reduziu os espaços de circulação, os quais ainda foram mais prejudicados com o uso intensivo de meios de transporte movidos à combustão (Lerner, 2013).

Os conflitos por espaços de qualidade para pedestres e para outros modos leves de deslocamento, como bicicletas e transporte público, tornaram-se mais acirrados após os anos de 1950. No Brasil, essa década é memorável porque se instalam as indústrias automobilísticas, que somente progrediram nos últimos 60 anos. Hoje, as cidades estão com problemas de trânsito, de congestionamentos e de acidentes que ameaçam o conforto, a confiabilidade e a dignidade de cidadãos (Lerner, 2013).

Em contrapartida, o que se constata para países emergentes é que a construção de cidades atendeu a interesses de empreendimentos imobiliários e gerou condições adversas de qualidade de vida e mobilidade. Logo, é preciso melhorar a vida nas cidades por meio da reconstrução de modelos de planejamento e, assim, criar condições para as pessoas caminharem, pedalarem e utilizarem o espaço público urbano (Gehl, 2013).

Outro ponto apontado por Chapadeiro (2011) é que, no Brasil, as políticas públicas relacionadas à mobilidade urbana favorecem o uso de automóveis, e não o transporte coletivo. Como esse processo vem ocorrendo há mais de 50 anos, as cidades apresentam problemas para a locomoção de pedestres e de ciclistas nos espaços mais disputados pelo comércio e indústrias.

Os caminhos sinalizam a necessidade de priorizar políticas e normas para amenizar os problemas mais prementes, como desestimular o tráfego de veículos motorizados individuais em determinados locais e promover o uso de veículos coletivos de qualidade e de outros modais mais humanizados. Faz-se necessária também a criação de espaços para caminhadas e bicicletas, o que facilita os movimentos de idas e vindas, além de cooperar para a saúde e bem-estar dos habitantes, caracterizando ações de sustentabilidade ambiental e social.

Para Gehl (2013), a sustentabilidade social é um conceito amplo e desafiador, pois trabalha as noções de inclusão de grupos da sociedade em espaços públicos seletivos e segregadores. No caso da mobilidade, tal igualdade seria atingida quando as pessoas caminhassem e andassem de bicicleta em combinação com o uso de transporte público.

Reafirmando a necessidade de priorização de transportes que garantam a sustentabilidade ambiental e social, em 3 de janeiro de 2012, foi aprovada a Lei Federal $n^{\circ} 12.587$, que institui as diretrizes para a Política Nacional de Mobilidade Urbana. Entre seus artigos que rezam sobre o desenvolvimento urbano, a norma exige a adoção de medidas que deem preferência aos modais de transportes não motorizados e designa orientações para os serviços de transporte coletivo e individual motorizado (Brasil, 2012).

Conforme cada Plano Diretor das cidades com mais de 20 mil habitantes, as municipalidades precisam organizar o espaço de forma a atender a esses novos preceitos de mobilidade. Em Curitiba, no Estado do Paraná, desde 1943, o planejamento foi meta dos prefeitos. 0 primeiro plano de urbanização foi feito com a colaboração do arquiteto Alfred-Donat Agache 
e reformulado em 1966, com última revisão em 2014. Pela legislação federal (Estatuto das Cidades Lei no 10.257, de 10 de julho de 2001, Brasil, 2001), a revisão do Plano Diretor deve ocorrer a cada 10 anos. Destaca-se a particularidade que ocorreu em 2014, que contou com a participação da população nas audiências promovidas pela Câmara Municipal de Curitiba (Curitiba, 2014).

O Plano Diretor de Curitiba define a função social da cidade e da propriedade urbana, assim como o funcionamento da cidade, de modo que a qualidade de vida para os habitantes seja alcançada. Na atualidade, os esforços municipais para uma cidade com 2 milhões de habitantes são para que ela seja mais humana, participativa, inovadora, inclusiva, funcional e sustentável para seus moradores (Curitiba, 2014).

Por isso, estão sendo priorizados programas e políticas orientadores do desenvolvimento urbano da cidade em relação às diretrizes de estrutura urbana, gestão democrática, habitação, instrumento de política urbana, meio ambiente e cultura, mobilidade e transporte, política de desenvolvimento econômico, política de desenvolvimento social, segurança e defesa social, e sistema de planejamento urbano (Curitiba, 2014).

Com a motivação de atender ao proposto pela Lei $n^{\circ} 12.587$ (Brasil, 2012), audiências sobre ciclomobilidade foram trabalhadas no Plano Diretor de Curitiba. $O$ intuito foi debater com a população questões relacionadas à necessidade da implementação do modal cicloviário no transporte diário da população, assim como sua integração ao sistema de transporte coletivo.

Nesse sentido, no primeiro semestre de 2014, em Curitiba, as primeiras experiências se deram com a criação da Via Calma, no trecho da Avenida Sete de Setembro, para favorecer a ciclomobilidade. Dentre os projetos do Instituto de Pesquisa Planejamento Urbano de Curitiba (IPPUC) de 2013, está o de estender essa iniciativa para outras avenidas da cidade, estimulando o uso da bicicleta como meio de transporte diário e oferecendo segurança e exclusividade aos usuários (IPPUC, 2013a). Conforme apontado por Miranda (2014), fazem parte dos planos da Prefeitura a definição e a ampliação de ciclorrotas, além da implantação de Vias Calmas na Avenida João Gualberto, sentido norte da cidade, e naquelas do eixo oeste, bem como o estabelecimento de parcerias para o desenvolvimento de pesquisas em ciclomobilidade.

O IPPUC segue seu trabalho por meio de pesquisas com usuários de bicicleta na Avenida Sete de Setembro, de modo a coletar informações para consolidar e melhorar esse projeto. Essa postura da municipalidade e dos usuários da Via Calma, além de favorecer a mobilidade, reduz a quantidade de emissão de gases do efeito estufa (GEE) na medida em que essas pessoas deixam de usar o transporte individual motorizado (Curitiba, 2015).

Esse conjunto de realizações e novidades estimulou a elaboração deste artigo, cujo debate se dá em torno de questões do planejamento urbano e mobilidade em grandes cidades, tendo como foco Curitiba. Esta cidade foi a primeira a ter um Instituto de Pesquisa e Planejamento, já nos anos de 1960, o qual até hoje busca cumprir as normas apresentadas no Plano Diretor, além de mantê-lo atualizado. Existe uma preocupação quanto ao aumento do número de veículos em circulação, especialmente no centro da cidade, onde há vias estreitas, adensamento e verticalização acentuada. Esse panorama definiu o objetivo da pesquisa, que foi o de levantar os pontos de vista de usuários, concernentes ao atendimento da função dos diferentes tipos de modais da Via Calma, da Avenida Sete de Setembro, em Curitiba, e sua importância para a mobilidade na cidade. Este trabalho é uma contribuição para os estudos urbanísticos, direito do ambiente, ordenamento do território, para difundir a importância da implantação de ações de mobilidade e para promover a inclusão de novos modais e vias, dando a possibilidade de escolha aos cidadãos.

Novos modelos de ação que visam aumentar a mobilidade de pessoas no espaço urbano são realmente do interesse de todos e reforçam o pensamento sistêmico e interdisciplinar.

\section{Gases do efeito estufa e a pegada de carbono do IPPUC}

A discussão sobre a emissão de GEE tem crescido mundialmente nos fóruns internacionais. 0 tema é fundamental, especialmente pelo fato da concentração desses gases ativar o aquecimento global. Além disso, consequências podem levar à diminuição da produção agrícola, à redução da disponibilidade de água, ao aumento de vetores de doenças, à extinção de determinadas espécies de animais, dentre outras convicções. Os GEE são aqueles que permitem a passagem da energia do sol e a retêm - como em uma estufa -, aumentando a absorção de energia da atmosfera (Dias \& Oliveira, 2013). 
Existe uma metodologia que contabiliza os gases emitidos de forma direta e indireta por organizações, observando o consumo de energia elétrica e de combustíveis. Em Curitiba, o IPPUC utilizou essa metodologia proposta pelo Programa Brasileiro GHG Protocol (Greenhouse Gas Protocol), que segue as normas ISO, e os métodos de quantificação do Painel Intergovernamental de Mudanças Climáticas (IPCC) para o cálculo da pegada de carbono do Instituto (Programa Brasileiro GHG Protocol, 2014). Foram realizados inventários de acompanhamento com acesso público (GVces, 2014).

Essa concepção de pesquisa realizada pelo IPPUC considerou emissões diretas e indiretas, dentre elas: o consumo de papel, o deslocamento de servidores de ida ao trabalho e volta para casa, os deslocamentos mais longos (como viagens a serviço do instituto), a frota de veículos utilizada, as emissões de sistemas de ar condicionado (e outros tipos de refrigeração), o consumo de energia elétrica, a aquisição de bens e serviços, o descarte de resíduos, entre outros (IPPUC, 2013b).

Segundo o levantamento, em 2012, a pegada de carbono gerada pelo IPPUC resultou em $264.327,89 \mathrm{~kg}$ de $\mathrm{CO}_{2}$. Dividindo-se pelo número de servidores, a pegada foi de 1,2 tonelada de $\mathrm{CO}_{2}$ para cada um. Considerando-se apenas o consumo de papel, chegou-se à quantia de 1.500 folhas $\mathrm{A} 4$ por servidor. No que diz respeito à água utilizada no Instituto no ano de 2012, corresponde a $14,3 \mathrm{~m}^{3}$, o mesmo que 712 galões de 20 litros por servidor (IPPUC, 2013b).

Em relação ao deslocamento diário para trabalho e casa, calculou-se que os veículos percorriam uma distância equivalente de $4.041 \mathrm{~km}$, o que corresponde ao maior impacto em relação ao valor total de quilos de carbono. Nesse sentido, a promoção do uso de bicicletas pode ser uma alternativa viável para a diminuição desses valores no município de forma geral, e não apenas em relação ao Instituto.

\section{Planejamento urbano e ciclomobilidade}

De acordo com Chapadeiro (2011), existem motivos relevantes que influenciam as cidades a instituir e favorecer o uso de modais de transporte diferenciados e investir em uma estrutura cicloviária. Se interrogados os cidadãos sobre suas escolhas de transporte, dificilmente o não uso contínuo da bicicleta como opção de transporte é ocasionado pela antipatia ao modal. Usualmente, os motivos mais comuns relatados por usuários que não optam pela bicicleta são a insegurança e a falta de infraestrutura viária.

Conforme o Ministério das Cidades (Brasil, 2007), as bicicletas eram os veículos individuais mais utilizados no país, constituindo na única alternativa ao alcance de todas as pessoas, não importando a renda, podendo ser usadas por aqueles que gozam de boa saúde, a partir da infância até a idade mais avançada. É interessante observar que as bicicletas têm durabilidade média de sete anos e que a frota brasileira se aproximou de 75 milhões de unidades em 2015.

Em contraponto, segundo a pesquisa do Instituto de Pesquisa Econômica Aplicada (IPEA, 2011), que investigou o meio de transporte mais utilizado para locomoção na cidade, os resultados mudaram em relação à pesquisa do Ministério das Cidades (Brasil, 2007) e apontaram para transporte público (44,3\%) e individual (carro, 23,8\%; moto, $12,6 \%$; a pé, $12,3 \%$; bicicleta, 7\%). Percebe-se, desse modo, a diminuição significativa no uso da bicicleta.

A circulação das bicicletas pela cidade pode ser realizada de diferentes formas. Segundo Chapadeiro (2011), existem quatro tipos principais de vias que contam com regulamentações para segurança do ciclista:

- Tráfego compartilhado: a movimentação das bicicletas é compartilhada com pedestres, normalmente utilizada em parques ou quando não é possível criar uma via exclusiva. Na Figura 1, tem-se o exemplo de Curitiba, que criou esse espaço em áreas de lazer, como os parques (Chapadeiro, 2011);

- Via ciclável: geralmente aplicadas em vias de menor tráfego, permite a circulação ao lado dos carros e apresenta sinalização horizontal para orientação (Chapadeiro, 2011). Na Figura 2, pode-se ver o exemplo aplicado em ruas de Los Angeles, nos Estados Unidos;

- Ciclofaixa: busca separar a circulação das bicicletas dos carros. Normalmente, localiza-se na borda direita das vias e possui sinalização mais evidente e contínua (Chapadeiro, 2011). Na Figura 3, vê-se a diferenciação das cores para evidenciar a circulação dos ciclistas; 


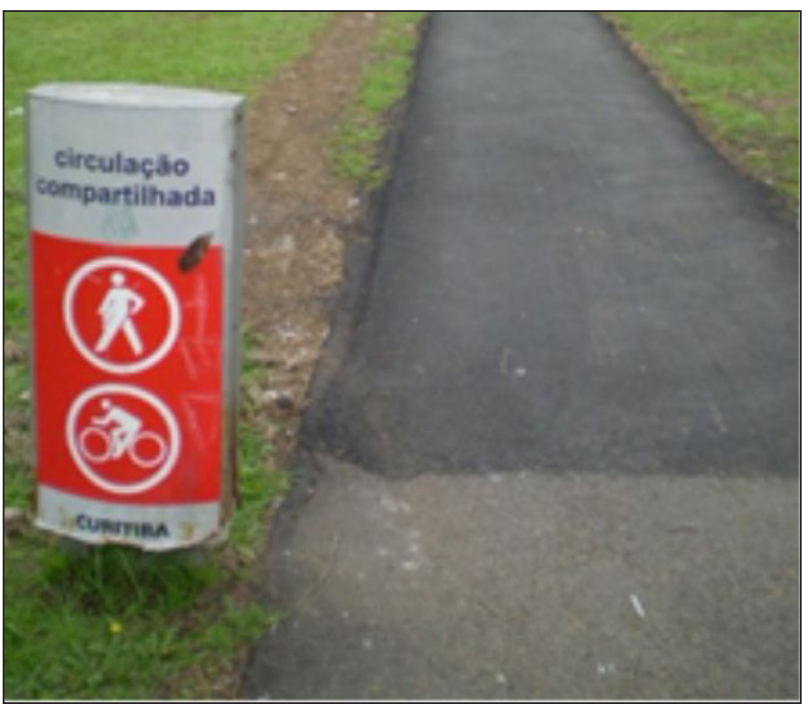

Figura 1 - Via de tráfego compartilhado com pedestres Fonte: Bicicletada Curitiba (2015).

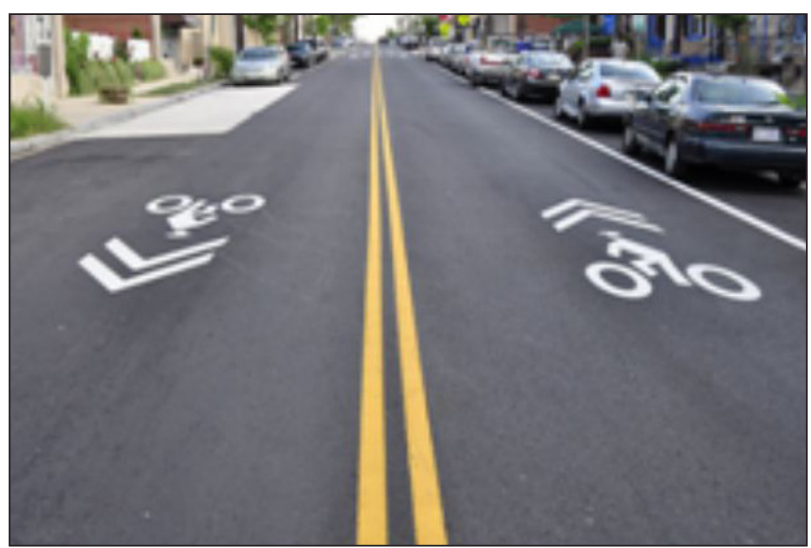

Figura 2 - Via ciclável Fonte: SDOT Blog (2015).

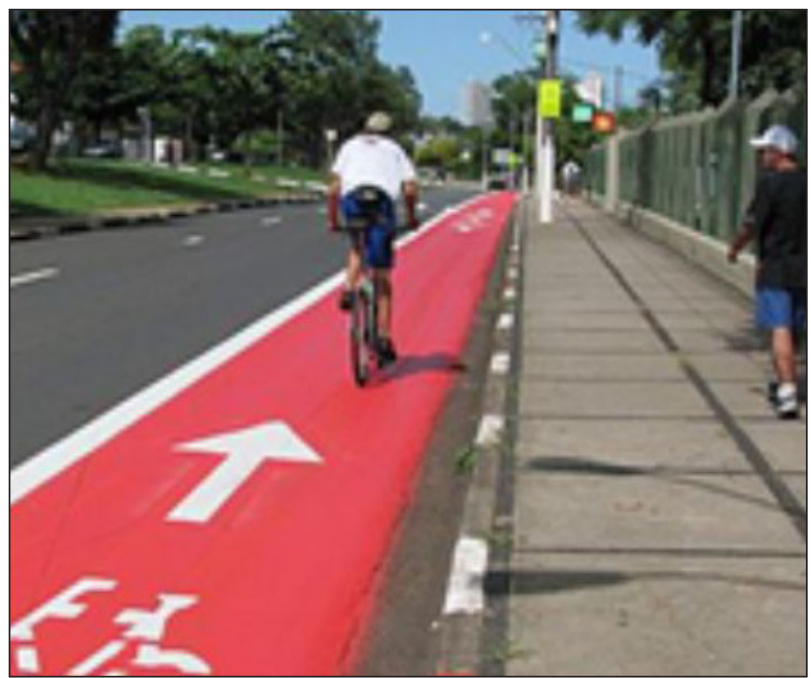

Figura 3 - Ciclofaixas em vermelho Fonte: Vá de Bici (2015).
- Ciclovia: é uma pista própria para circulação de bicicletas separada fisicamente do fluxo de veículos motorizados (Chapadeiro, 2011). Na Figura 4, podem-se ver as divisões com grades para separar o fluxo das bicicletas.

Essas soluções exemplificadas procuram garantir a segurança do ciclista em sua mobilidade em centros urbanos, e os agentes públicos necessitam analisar as rotas possíveis e os tipos mais adequados para bairros e centros históricos ou comerciais.

\section{Ciclomobilidade em Curitiba}

A Prefeitura de Curitiba tem procurado se aproximar da realidade do uso das bicicletas como meio de transporte usado por esportistas e trabalhadores, sobretudo porque elas circulam frequentemente nas faixas exclusivas dos ônibus expressos, veículos pesados e que alcançam velocidade considerada alta. Por isso foi feita uma pesquisa, em 2013, por amostragem na Avenida Sete de Setembro com os ciclistas, que confirmou esta assertiva: $63 \%$ deles utilizavam a canaleta destinada aos ônibus expressos (IPPUC, 2013a). Como essa avenida possui, além das canaletas exclusivas, mais duas outras pistas, foi pensado em implantar a Via Calma nesses espaços em que circulam os veículos individuais motorizados. Mas ainda persistem os usos dos ciclistas em ambos os espaços, conforme pode ser observado nos dizeres da faixa colocada no alto da via (Figura 5). 0 pedido da Prefeitura - "Ciclista, não se arrisque [sua vida] na canaleta, pedale na Via Calma" é com o intuito de conscientizá-lo de que existe agora um espaço exclusivo para ele.

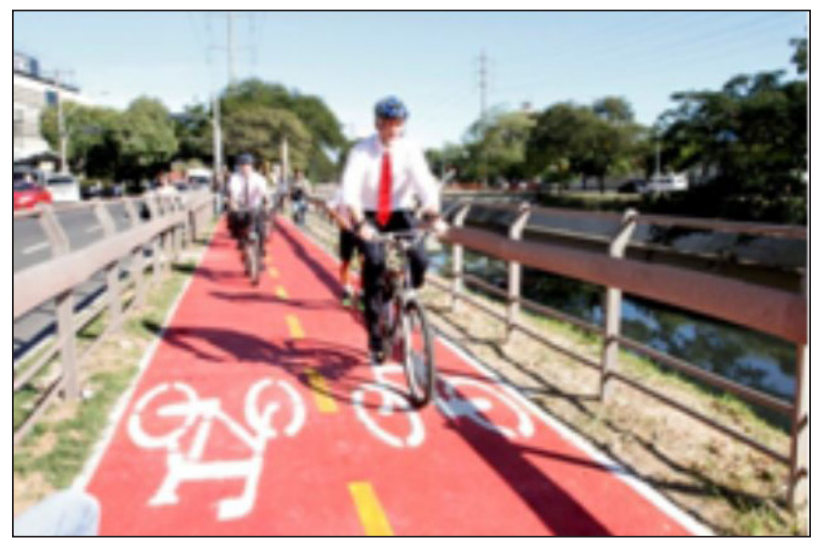

Figura 4 - Ciclovia com separacãa da via de automóveis Fonte: Diário do Centro do Mundo (2015). 

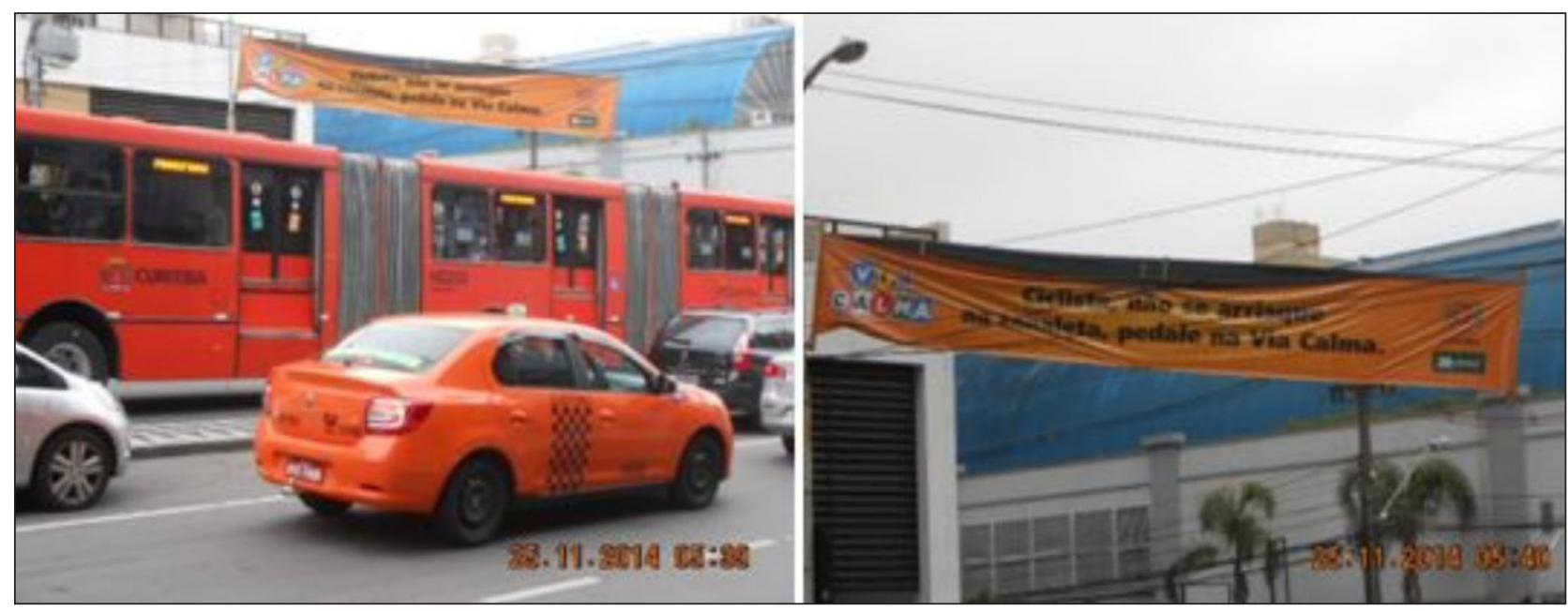

Figura 5 - Via Calma com alerta aos ciclistas Fonte: Autoria própria (2015).

De acordo com o IPPUC (2013a), a Avenida Sete de Setembro compreende um dos eixos centrais de deslocamento da cidade e, segundo pesquisa realizada pelo instituto, concentra o fluxo de ciclistas de 54 bairros diferentes. 0 trecho da Via Calma, implantada entre a Rua Mariano Torres e a Praça do Japão, abrange uma extensão de 6,3 km (Curitiba, 2014). É a primeira Via Calma de Curitiba e foi idealizada para trazer novas opções no contexto da mobilidade, resgate do trânsito humanizado, priorização do ciclista, e proteção do pedestre. Os ciclistas transitam à direita da via sobre área demarcada em linha tracejada, e a velocidade máxima permitida para carros e motos é de $30 \mathrm{~km} / \mathrm{h}$, harmonizando o trânsito e facilitando o deslocamento intermodal.

Ainda na Via Calma da Avenida Sete de Setembro, foram implantadas bicicaixas, uma área especial de parada para bicicletas nos semáforos, entre a faixa de pedestres e a área de veículos motorizados. As bicicaixas têm as seguintes finalidades: protegem e priorizam os ciclistas quando abre o sinaleiro dos veículos, garantem mais segurança aos ciclistas nos cruzamentos e dão prioridade aos ciclistas para realizar conversões.

O Plano Diretor cicloviário de Curitiba de 2013 (IPPUC, 2013a) previa, para 2015, obras para implantação da via ciclável na Avenida Manoel Ribas, com requalificação do trecho de aproximadamente 2,65 km entre o Cemitério da Santa Felicidade e o Contorno Norte. 0 projeto contemplava vias cicláveis e previa a extensão da estrutura cicloviária de $5,5 \mathrm{~km}$. Outros projetos em implantação na cidade eram:
Avenida Marechal Floriano Peixoto com 3,84 km, Linha Verde Sul/Sul com 1,76 km e Avenida Comendador Franco com 9,91 km.

Em função dessas ações da Prefeitura Municipal de Curitiba (PMC) e do IPPUC, e das discussões sobre a revisão do Plano Diretor de 2004, membros do Grupo de Estudos Tecnologia e Meio Ambiente (TEMA), da Universidade Tecnológica Federal do Paraná (UTFPR), dedicaram-se a fazer uma pesquisa a respeito do ponto de vista dos usuários da Via Calma, da Avenida Sete de Setembro. A pesquisa do TEMA é motivada pela parceria entre a PMC e IPPUC com a UTFPR. Em reunião com membros do IPPUC, foi sugerido ao grupo desenvolver a pesquisa para auxiliar o Instituto na avaliação das medidas para implantação da Via Calma. O IPPUC, posteriormente, também realizou levantamento com especificidades e diferenciações que foram retomadas neste artigo como subsídios para comparação de dados na discussão (IPPUC, 2014).

\section{Metodologia}

Para identificar o ponto de vista dos usuários sobre a Via Calma na Avenida Sete de Setembro, em Curitiba, em relação ao seu funcionamento, utilizou-se a técnica de preferência declarada (TPD). Conforme Nunes (2012), essa técnica é o método mais prático e confiável para análise de investimentos em infraestrutura e previsões de demanda quando um novo tipo de serviço é introduzido no mercado. A TPD fundamenta-se em entrevistas, mediante as 
quais são oferecidas opções que se aproximem da realidade, e o entrevistado escolherá a melhor delas. Todas as opções escolhidas por ordem de preferência são utilizadas como informação. A informação obtida com a técnica conduz o planejador de transporte a estimar como os indivíduos reagem quando são colocados diante de mudanças em um determinado tipo de serviço (Nunes, 2012).

As principais características da TPD apontadas por Nunes (2012) são:

a) Ao entrevistado é apresentada uma série de opções (com alternativas hipotéticas). 0 conjunto de opções precisa ser definido tomando-se como base os fatores ou os atributos que estão influenciando de maneira mais contundente o problema analisado;

b) Cada opção é constituída por um conjunto de atributos que identifica o serviço, e essa opção é representada por um cartão. Dão-se alternativas hipotéticas a cada atributo integrante dos cartões (opções);

c) Os valores das alternativas desses atributos são especificados pelo investigador. Esses valores devem aproximar-se o quanto possível da realidade, e nunca muito numerosos, pois isso tornaria a escolha cansativa e, por consequência, dados imprecisos;

d) As opções são especificadas com base em um projeto de experimentos, no qual se assegura que a variação de um atributo seja estatisticamente independente do outro;

e) Os entrevistados declaram suas preferências diante das opções por meio de três formas de classificação de TPD: rating (avaliação), ranking (ordenação) e escolha discreta.

Dentre as vantagens do uso da TPD, segundo Kroes \& Sheldon (1988 apud Nunes, 2012), citam-se aquelas que:

1. Permitem ao entrevistado a possibilidade de identificar como os usuários irão comportar-se diante das diferentes opções;

2. De uma entrevista são colhidos vários dados individuais que, posteriormente, serão utilizados como informações na modelagem matemática;

3. A técnica mostra-se bastante eficiente mesmo quando as variáveis de serviço não se mostram de forma quantitativa, isto é, os valores dos atributos são subjetivos.

Na elaboração das questões, tomou-se como base o estudo de mobilidade desenvolvido por Silva (2013) em Porto Alegre, no Rio Grande do Sul. Após aplicação de questionário-piloto e realizadas as alterações, este foi divulgado e compartilhado utilizando-se as redes sociais na internet. Entre os principais grupos no qual foi publicado, estão os estudantes, professores, shoppings, taxistas, associação da Urbanização de Curitiba S/A (URBS), praças, sindicatos de vigilantes e guardas municipais, hotéis, campus de uma universidade, entre outros. Partiu-se da hipótese que fossem prováveis usuários da Avenida Sete de Setembro.

Com intuito de reduzir gastos e obter um número adequado de respostas, foi aplicada a técnica da "Bola de Neve", utilizando-se uma amostragem não probabilística por conveniência. Nessa técnica, para cada respondente foi solicitado que enviasse o questionário a outros possíveis participantes (Hamza \& Dalmarco, 2011).

Foram abordadas perguntas destinadas à identificação socioeconômica do entrevistado, modalidades de transporte utilizadas, padrões de viagem dos usuários de bicicleta, importância atribuída aos aspectos relacionados à segurança para o uso da bicicleta e aspectos importantes para o estímulo ao uso da bicicleta. 0 questionário foi composto por quatro questões para coleta de dados relativos à faixa etária, renda familiar, sexo e grau de instrução, além de oito questões para a avaliação da implantação da Via Calma na Avenida Sete de Setembro, em Curitiba. Dentre essas questões, três eram perguntas de múltipla escolha com mostruário; duas questões, dicotômicas com Sim e Não; duas questões, com grau de concordância; duas questões, abertas, segundo classificação de Marconi \& Lakatos (2003).

Para análise das questões com grau de concordância, utilizou-se a escala Likert, aplicando-se o ranking médio (RM), conforme citado por Oliveira (2005). O RM é obtido pela média ponderada, observando-se a frequência de respostas, multiplicada pelo valor na escala (1 a 5), dividido pelo número de respondentes. No questionário, encontravam-se as opções: (1) discordo completamente; (2) discordo parcialmente; (3) não tenho opinião a respeito; (4) concordo parcialmente; (5) concordo completamente. Quanto às questões abertas, utilizou-se a análise de conteúdo, mediante a 
compilação das respostas, identificando os termos-chave para cada resposta e sua frequência.

\section{Resultados}

Nesta seção, serão apresentados o perfil da amostra e a tabulação dos resultados obtidos.

\section{Perfil da amostra}

O questionário foi aplicado a 90 respondentes. As questões e as respostas serão analisadas a seguir. A respeito da faixa etária: $1 \%$ do universo total (1 entrevistado) tinha até 18 anos de idade; $52 \%$ (47 pessoas), de 18 a 25 anos de idade; $23 \%$ (21 respondentes), entre 25 e 35 anos; $17 \%$ (15 entrevistados), de 35 a 50 anos de idade; e 7\% (6 respondentes), idade acima de 50 anos (Figura 6). Esse resultado é relevante para apontar a importância do modal para aquelas pessoas que estão na faixa etária estudantil e de trabalho.

Sobre a renda familiar, dentre os 90 entrevistados: 5 respondentes $(6 \%)$ apresentavam renda familiar de até $R \$ 1.448,00 ; 13$ pessoas (14\%), entre $R \$ 1.448,00 \mathrm{e}$ $\mathrm{R} \$ 2.896,00 ; 44$ entrevistados (49\%), entre $\mathrm{R} \$ 2.896,00$ e $R \$ 7.240,00 ; 20$ pessoas (22\%), entre $R \$ 7.240,00$ e $\mathrm{R} \$ 14.480,00$; e 8 respondentes (9\%), renda familiar acima de $\mathrm{R} \$ 14.480,00$ (Figura 7). Esses resultados apontam que pessoas com renda média em torno de R $\$ 2$ mil, equivalente a três salários mínimos no espectro nacional, fazem uso do transporte porque provavelmente os custos das outras modalidades interfiram no orçamento familiar.

Tratando do sexo dos entrevistados, $56 \%$ (50 respondentes) eram homens, e 44\% (40 respondentes), mulheres, conforme Figura 8. As questões de gênero não interferiram na escolha do modal, pois ambos os sexos aderiram a essa modalidade.

Abordando o grau de instrução dos entrevistados: 36\% (32 entrevistados) possuíam superior incompleto; 63\% (57 pessoas), superior completo; $1 \%$ (1 entrevistado), ensino médio completo (Figura 9). Os dois grupos se equivaleram quanto à capacitação e experiência com o estudo universitário.

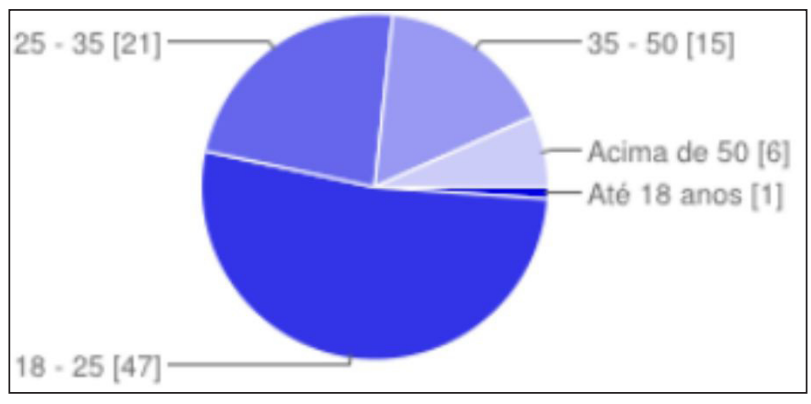

Figura 6 - Respostas quanto à faixa etária Fonte: Autoria própria (2015).

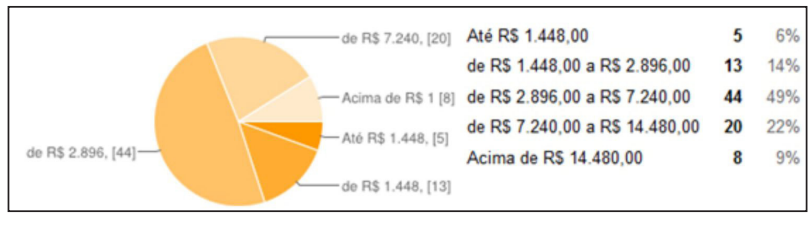

Figura 7 - Respostas quanto à renda familiar Fonte: Autoria própria (2015).

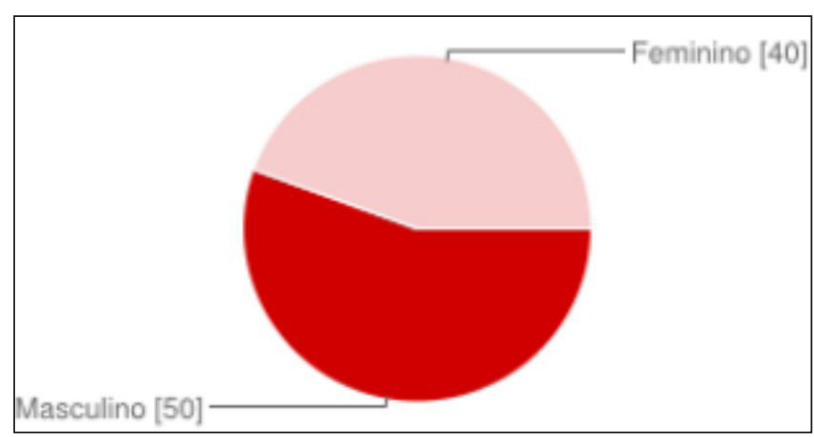

Figura 8 - Respostas quanto ao sexo Fonte: Autoria própria (2015).

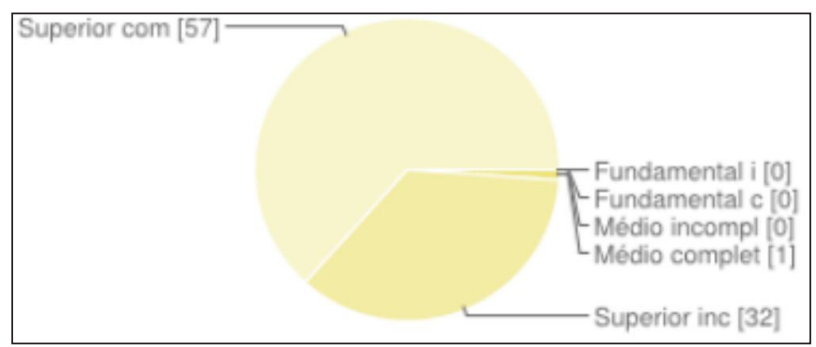

Figura 9 - Respostas quanto ao grau de instrução Fonte: Autoria própria (2015).

\section{Tabulação dos resultados obtidos}

A questão 1 para a avaliação da implantação da Via Calma na Avenida Sete de Setembro, em Curitiba, elencou os motivos para a utilização pelos entrevistados. Para 41 respondentes, o deslocamento com bicicleta 
era para realizar atividades estudantis, representando $46 \%$ do universo de entrevistados. Para deslocamento por motivo de trabalho, foram 36 respondentes (40\%). Já 28 pessoas, equivalente a 31\%, utilizavam o modal para lazer. Somente 7 entrevistados, ou seja, 8\%, utilizavam para deslocamento por outros motivos não abordados nas opções de respostas do questionário (ver os resultados sintetizados na Figura 10). Quando especificados os outros motivos, o que predominou foi a residência nas proximidades da Avenida Sete de Setembro, pois a Via Calma facilitou os movimentos de ida e vinda com a bicicleta.

A questão 2 foi sobre os principais meios de transporte utilizados na Avenida Sete de Setembro pelos entrevistados. Do universo de 90 respondentes, 23 (26\%) utilizavam bicicleta; 4, motocicletas; 51 (57\%), carro; 41 (46\%), ônibus; 49 (54\%) se deslocavam a pé; 2 pessoas (2\%) usavam outros meios de transporte, como skate, por exemplo. Na Figura 11, o ônibus concorre com o carro e com a caminhada a pé porque é possível fazer compras, ir e vir para o centro da cidade, dirigir-se aos bairros com pelo menos essas três opções - porém mais outras três estão apontadas como viáveis.

Na questão 3, que tratou sobre o uso da bicicleta como meio de transporte, 26 respondentes (29\%) já a usavam como meio de transporte, e 64 (71\%), não, como pode ser visto na Figura 12. Ainda que os usuários diversifiquem a modalidade escolhida para deslocamento, a bicicleta é bastante representativa, se comparada com as respostas representadas na Figura 11.

Complementando a ideia, a questão 3.1 foi realizada para o universo de entrevistados que não usava a bicicleta como meio de transporte. Perguntou-se se trocariam o atual modo de transporte pela bicicleta. Dos respondentes, 33 afirmaram que sim e 31 disseram que não. Isso aumentaria de 26 pessoas (Figura 11) para 57 pessoas o universo de usuários desse modal.

Na questão 4, na qual se pedia ao respondente assinalar "as opções que mais atrapalham o uso da bicicleta na Avenida Sete de Setembro", a que se destacou foi o "risco de acidentes". Seguiram em ordem de importância para os respondentes: o "risco de assalto/roubo, ausência de paraciclos, clima, roupas inadequadas, distância e topografia" (Figura 13). Os respondentes acrescentaram três respostas não englobadas nas opções: ausência de sombras no caminho (árvores na calçada), motociclistas invadindo o espaço dos ciclistas e problemas na coluna. Segundo esses resultados, a Prefeitura ainda poderia melhorar a questão dos estacionamentos, ao partilhá-los com os espaços ocupados pelos automóveis, aplicar multa para os infratores (já está sendo aplicada para alguns casos) e disponibilizar vigilância pela guarda municipal.

A questão 5, "Você considera que a implantação da Via Calma contribui para o aumento da utilização de bicicletas na Avenida Sete de Setembro?", apresentou uma resposta positiva. Aplicando-se o RM, obteve-se o valor de 3,99, ou seja, as respostas obtidas aproximavam-se - em média - mais do "concordo parcialmente", conforme pode ser visto na Figura 14.

A questão 6, "Você considera positiva a implantação da Via Calma?", também foi avaliada pelo grau de concordância: $46 \%$ dos pesquisados concordavam plenamente. Com a aplicação do RM, obteve-se o valor de 3,95, e, assim como na questão anterior, a média de

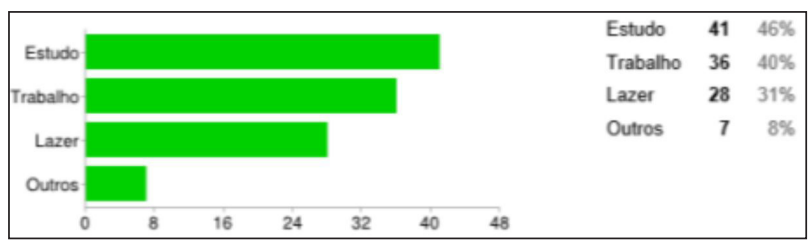

Figura 10 - Respostas quanto ao principal motivo para utilização da Avenida Sete de Setembro no deslocamento Fonte: Autoria própria (2015).

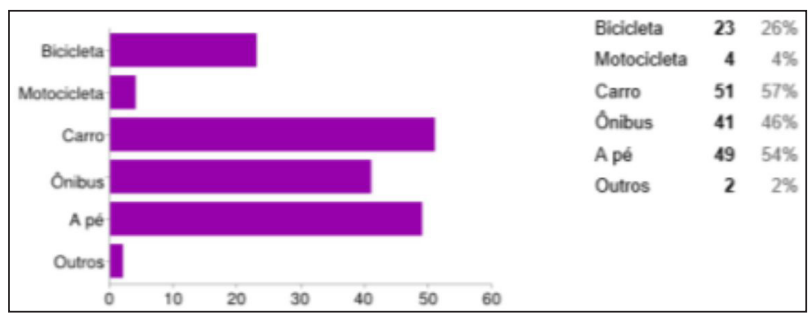

Figura 11 - Respostas quanto aos principais meios de transporte para utilização da Avenida Sete de Setembro Fonte: Autoria própria (2015).

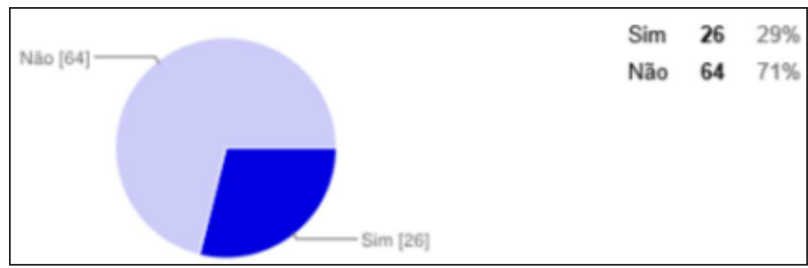

Figura 12 - Respostas quanto ao uso da bicicleta como meio de transporte Fonte: Autoria própria (2015). 


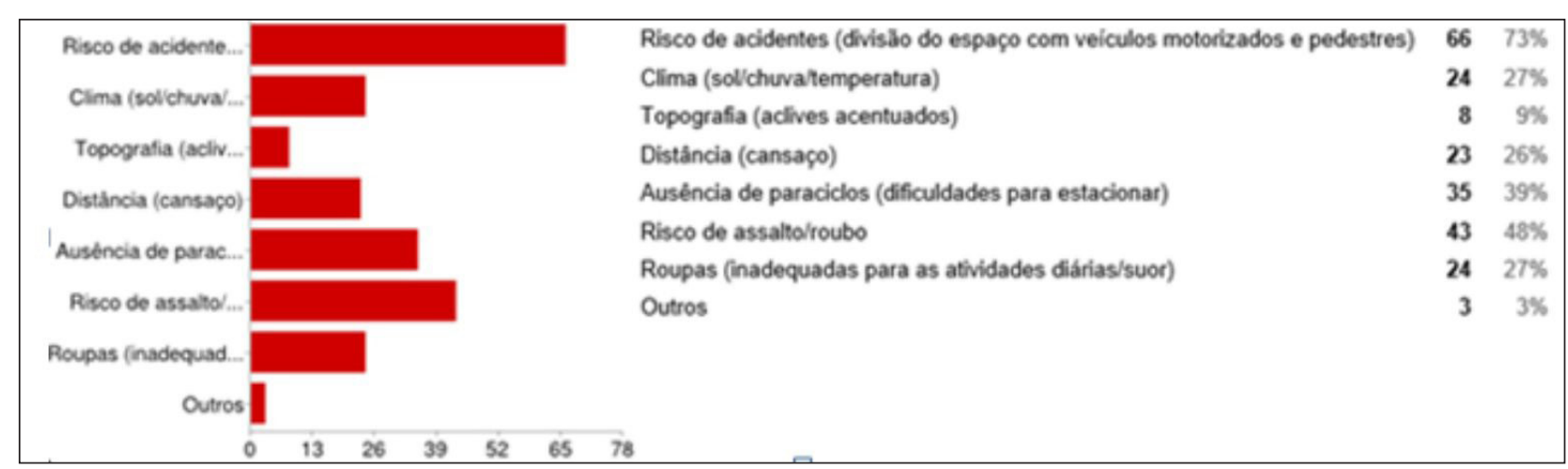

Figura 13 - Respostas quanto às opç̃oes que mais atrapalham o uso da bicicleta na Avenida Sete de Setembro Fonte: Autoria própria (2015).

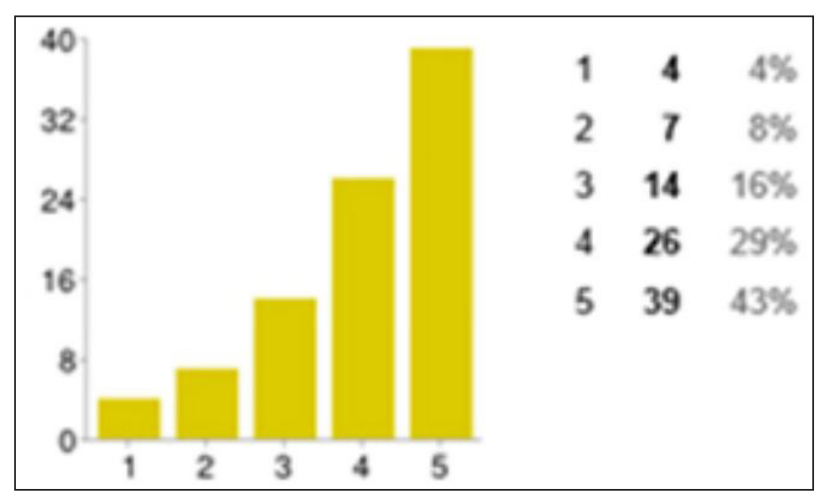

Figura 14 - Respostas quanto ao grau de concordância em relação à contribuição da Via Calma para o aumento do uso de bicicletas na Avenida Sete de Setembro Fonte: Autoria própria (2015).

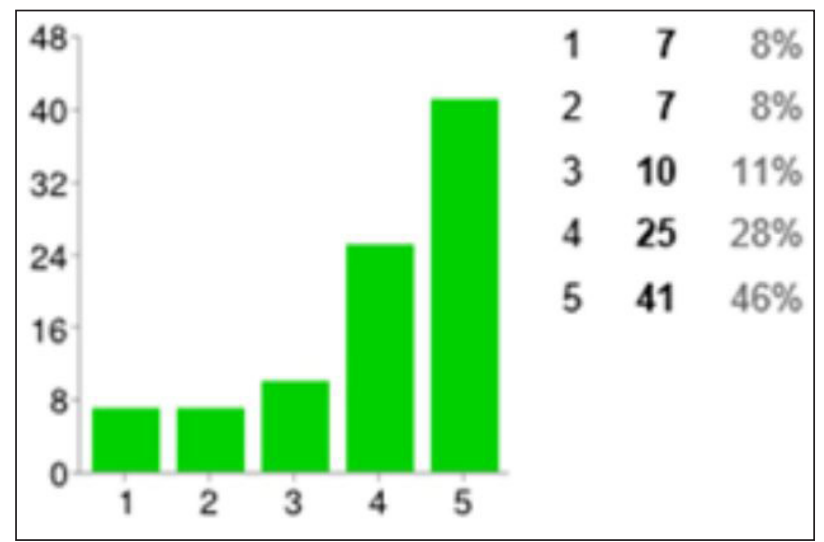

Figura 15 - Respostas quanto ao grau de concordância em relação à implantação da Via Calma como positiva Fonte: Autoria própria (2015).

respostas aproximou-se do "concordo parcialmente", como visto na Figura 15.

As questões 7 e 8 eram opcionais e discursivas, e se referiam aos principais pontos positivos e negativos da Via Calma. Dos 90 respondentes, 45 apontaram a positividade da iniciativa, enquanto 43 concentraram-se nos pontos negativos. Dentre os assuntos levantados como positivos, estão a melhoria no trânsito, a qualidade de vida, o meio ambiente, o compartilhamento da via, a promoção do uso da bicicleta, a segurança, a conscientização, a mobilidade, a infraestrutura e a sustentabilidade. Ao contrário, aqueles que consideraram a iniciativa negativa justificaram suas respostas com os argumentos da insegurança, falta de conscientização dos motoristas, dificuldades do trânsito, falta de estrutura e redução da frequência de clientes no comércio.

\section{Discussão}

Nesta seção, serão discutidos os resultados obtidos e apresentados nas formas de textos, gráficos e figuras. Quanto à ferramenta utilizada para a coleta de dados, pôde-se perceber que determinados grupos escolhidos não se manifestaram nem retornaram o questionário. A maior parte dos respondentes concentrou-se no grupo da comunidade acadêmica. Foram participantes com faixa etária entre 18-35 anos (68\%), renda familiar entre 4 e 20 salários mínimos (71\%) e grau de instrução com ensino superior incompleto ou completo (99\%).

Comparando-se a pesquisa feita pelo IPPUC (2014) com os ciclistas, ela estaria em consonância com esta pesquisa no que tange à faixa etária participante. Com relação ao grau de instrução, a pesquisa do IPPUC (2014) destaca que 20,8\% dos ciclistas possuíam segundo grau completo, e que 21,9 e $26 \%$, terceiro grau incompleto e completo, respectivamente. 
Ratificando o que foi citado na questão 1, 46\% dos 90 respondentes afirmaram utilizar a Via Calma para se dirigir a ambientes estudantis, e outros $40 \%$ (36, dos quais 26 tinham ensino superior completo), para trabalho. Já na pesquisa do IPPUC (2014), 71,5\% dos ciclistas utilizavam a Via Calma para trabalho, e somente $13,2 \%$, para estudo.

Entre os principais meios de transporte, na questão 2 , percebe-se que a maioria ainda utilizava o carro (57\%), mas também consideravam, ou já utilizaram, outros meios, pois a opção "a pé" obteve $54 \%$ - a segunda maior -, seguida de ônibus com $46 \%$ e bicicleta - foco da análise do uso da ciclofaixa - com $26 \%$. Conclui-se que, na relação entre os modais com duas rodas - a bicicleta obteve 26 respostas, enquanto que as motocicletas, 4 - existe uma tendência à adoção da bicicleta quando se pretende utilizar um veículo pequeno.

Nesse sentido, a questão 3 apontou que 29\% dos entrevistados já utilizavam a bicicleta como meio transporte e que, dos 64 respondentes que não a utilizavam, 33 trocariam o atual modo de transporte pela bicicleta, ou seja, há uma disposição no incremento do uso da bicicleta como meio transporte, conforme já foi comentado.

Há probabilidades de que esse número reduzido ocorra porque ainda se fazem presentes empecilhos para o uso da bicicleta na Avenida Sete de Setembro. De acordo com os respondentes, os principais fatores podem estar elencados nas respostas da quarta questão: o risco de acidentes devido à divisão de espaço com veículos e pedestres, o risco de assalto e roubo, e a ausência de paraciclos, ocasionando dificuldades para estacionar. Esses resultados corroboram o que afirma Chapadeiro (2011) sobre a insegurança e a falta de infraestrutura como principais fatores do não uso da bicicleta.

Ainda em relação à questão 4 , outros temas foram citados, como o clima, o cansaço por causa da distância e as roupas inadequadas devido ao suor. Esses itens podem fazer parte de uma discussão sobre infraestrutura, como apontado em uma das respostas abertas, quando foi mencionada a falta de árvores no caminho, o que promoveria sombra e deixaria o percurso mais agradável. Da mesma forma, a questão de motociclistas invadindo o espaço prova a questão da insegurança, mas também que é necessária uma maior campanha quanto à conscientização das escolhas e respeito aos modais usados de forma adequada, dado o fato de a via ser compartilhada, e não exclusiva. São regras de convivência com a diversidade e a busca pela igualdade de oportunidades na apropriação dos espaços públicos.

No que tange à questão 5 , que abordou a contribuição da Via Calma para o aumento na utilização de bicicletas na Avenida Sete de Setembro, os respondentes, em média, concordaram parcialmente. Contudo, ressalta-se que $43 \%$ concordaram plenamente com tal reforço, ou seja, esse resultado vai ao encontro do que foi apontado pelo IPPUC (2013a), pois a implantação de uma forma mais segura de utilização das bicicletas pode ajudar na promoção do uso delas no transporte diário.

Ainda, na avaliação dos respondentes na pergunta 6, em média, eles concordaram parcialmente com a implantação da Via Calma. Porém, deve-se ressaltar que quase metade $(46 \%)$ concordou plenamente, o que pode indicar que grande parte dos usuários entende a necessidade de buscar alternativas de transporte e mudar o foco que foi dado ao automóvel durante mais de 50 anos, conforme apontado por Chapadeiro (2011).

Em relação aos pontos positivos, das 41 respostas obtidas na questão 7 - cujos percentuais são apresentados a seguir -, a partir da ponderação da frequência, foi possível categorizar os termos-chave mais mencionados em ordem decrescente:

1. Segurança $(34,1 \%)$ : destacam-se como principais pontos relacionados ao aumento da segurança o espaço reservado para ciclistas e a diminuição da velocidade dos veículos;

2. Infraestrutura (31,7\%): a pintura e a sinalização do espaço destinado ao uso das bicicletas promovem um incremento de ciclistas, ao se sentirem mais seguros com uma via destinada a eles;

3. Mobilidade (22\%): a promoção da bicicleta como meio de transporte diminuindo a utilização de carros.

No que diz respeito à questão 8, das 41 respostas obtidas, os principais pontos negativos levantados, percentualmente por sua frequência, foram:

1. Insegurança (51,2\%): destacam-se a necessidade de dividir o espaço e andar próximo a outros modais (carros, motos, ônibus), além da necessidade de um semáforo exclusivo para aumentar a segurança dos cruzamentos; 
2. Dificulta o trânsito $(36,6 \%)$ : os principais pontos foram a diminuição do espaço para os carros e a necessidade de andar em uma velocidade menor;

3. Falta de conscientização $(29,3 \%)$ : neste quesito, deve-se destacar que, em uma visão tanto do condutor dos veículos quanto do ciclista, falta conscientização de ambas as partes. Nesse sentido, por parte dos motoristas, os ciclistas não respeitam os sinais e andam na contramão; já na visão do ciclista, os motoristas invadem o espaço e andam em alta velocidade.

Percebe-se que os principais pontos positivos promovem a utilização da bicicleta, enquanto que os pontos negativos dizem respeito à visão do ciclista, quando fala em insegurança em relação aos outros modais, mas, ao mesmo tempo, uma visão do usuário dos outros modais, quando se destaca o fato de atrapalhar o trânsito e a falta de consciência dos ciclistas.

Pode-se indicar como principal fator, tanto entre pontos positivos quanto negativos, a segurança que engloba os demais termos destacados. Nesse contexto, é possível apontar que, nos pontos positivos, a melhoria da infraestrutura aumenta a segurança e que, nos pontos negativos, a falta de conscientização aumenta a insegurança daqueles que se propõem a utilizar a bicicleta.

Ao retomar as questões de emissão de carbono, na medida em que os ciclistas sentirem-se mais seguros, com leis de trânsito mais respeitadas, consequentemente, haverá redução de emissões por parte desses usuários que escolheram o modal da bicicleta, sobretudo os moradores do entorno, que seriam os que têm maior potencial de adesão. Com os novos prédios que cresceram em altura no trecho da Via Calma, a Prefeitura teria muito sucesso colocando locais para estacionamento e sinaleiros exclusivos, que funcionariam conjuntamente com os dos carros, reforçando os direitos de circulação de todas as transversais. Outro ponto relevante seria reduzir a velocidade dos ônibus que trafegam nas canaletas exclusivas para dar o direito e a segurança aos pedestres e aos ciclistas que desejam escolher outras ruas que não sejam a Via Calma.

\section{Conclusões}

Em relação ao objetivo definido, acredita-se que a pesquisa contribuiu para traçar o perfil, assim como apontar as preferências dos usuários da Via Calma, em consonância com as pesquisas desenvolvidas anteriormente.

A concentração de respondentes em determinados grupos do perfil pode ser resultado da técnica e das ferramentas utilizadas - redes sociais e demais meios eletrônicos. Entende-se que, por esse motivo, a amostra não seja representativa para generalização; porém, para expandir os resultados, recomenda-se a aplicação de questionários presencialmente a fim de obter respostas de demais perfis, como, em especial, o grau de instrução.

Em relação às possibilidades de trabalhos futuros, acredita-se que, com a implantação da Via Calma em demais trechos da cidade, o emprego da pesquisa poderá ser refeito para comparação dos resultados e que, quanto mais tempo a Via Calma da Avenida Sete de Setembro tiver como experiência, mais usuários passarão a utilizá-la e poderão representar um novo perfil, assim como ter diferentes percepções a serem analisadas e comparadas.

\section{Referências}

Bicicletada Curitiba. (2015). Curitiba. Recuperado em 18 de março de 2015, de http://bicicletadacuritiba.files. wordpress.com/2008/10/pa0700652.jpg

Brasil. (2001, 10 de julho). Lei no 10.257, de 10 de julho de 2001. Regulamenta os artigos 182 e 183 da Constituição Federal, estabelece diretrizes gerais da política urbana e dá outras providências. Brasília: Diário Oficial da União.

Brasil. Ministério das Cidades. (2007). Caderno de referência para elaboração de Plano de Mobilidade por Bicicleta nas Cidades (Coleção Bicicleta Brasil, 1). Brasília: Secretaria Nacional de Transporte e da Mobilidade Urbana.

Brasil. (2012, 4 de janeiro). Lei $n^{\circ} 12.587$, de 03 de janeiro de 2012. Institui as diretrizes da Política Nacional de Mobilidade Urbana. Brasília: Diário Oficial da União.

Centro de Estudos em Sustentabilidade - GVces. (2014). Programa Brasileiro GHG Protocol: método. São Paulo. Recuperado em 18 de março de 2015, de https://cms-ghg. herokuapp.com/metodo-ghg-protocol.

Chapadeiro, F. C. (2011). Limites e potencialidades do planejamento cicloviário: um estudo sobre a participação cidadã (Dissertação de mestrado). Universidade de Brasília, Brasília. 
Curitiba. Prefeitura Municipal. (2014). Plano Diretor. Curitiba. Recuperado em 9 de setembro de 2014, de http://www. curitiba.pr.gov.br/planodiretor.

Curitiba. Prefeitura Municipal. (2015). IPPUC lança plano para reduzir emissão de gases de efeito estufa. Curitiba. Recuperado em 18 de março de 2015, de http://www. curitiba.pr.gov.br/noticias/ippuc-lanca-plano-para-reduziremissao-de-gases-de-efeito-estufa/35671.

Diário do Centro do Mundo. (2015). Recuperado em 18 de março de 2015, de http://www.diariodocentrodomundo. com.br/wp-content/uploads/2014/05/ciclovia.jpg

Dias, R., \& Oliveira, T. L. G. (2013). A contribuição das empresas do Estado do Paraná para a redução dos gases de efeito estufa. Revista NUPEM, 5(9), 141-150.

Gehl, J. (2013). Cidades para pessoas (2. ed.). São Paulo: Perspectiva.

Hamza, K. M., \& Dalmarco, D. A. S. (2011). A evolução do movimento do Consumo Consciente e seus impactos para as organizações: um estudo exploratório. In Anais do XIV Seminários em Administração. São Paulo: SemeaAd.

Instituto de Pesquisa e Planejamento Urbano de Curitiba IPPUC. (2013a). Plano diretor cicloviário de Curitiba 2013. Curitiba: IPPUC. Recuperado em 08 de agosto de 2014, de http://www.ippuc.org.br/.

Instituto de Pesquisa e Planejamento Urbano de Curitiba - IPPUC. (2013b). IPPUC mede a emissão de gases do efeito estufa em suas atividades. Curitiba: IPPUC. Recuperado em 18 de março de 2015, de http://www.ippuc.org.br/ mostrarnoticia.php?noticia $=$ cd_noticias $=127 \&$ ampliar $=$ sim .

Instituto de Pesquisa e Planejamento Urbano de Curitiba - IPPUC. (2014). Pesquisa com usuários de bicicleta na Via Calma da Avenida Sete de Setembro. Curitiba: IPPUC. Recuperado em 18 de março de 2015, de http://www. ippuc.org.br/visualizar.php?doc=http://admsite.ippuc. org.br/arquivos/documentos/D235/D235_004_BR.pdf.
Instituto de Pesquisa Econômica Aplicada - IPEA. (2011). Sistema de indicadores de percepção social (SIPS): mobilidade urbana. Brasília. Recuperado em 11 de março de 2016, de http://www.ipea.gov.br/portal/images/stories/PDFs/ SIPS/110124_sips_mobilidade.pdf.

Lerner, J. (2013). Prólogo à edição brasileira. In J. GEHL. Cidades para pessoas (2. ed.). São Paulo: Perspectiva.

Marconi, M. A., \& Lakatos, E. M. (2003). Fundamentos de metodologia científica (5. ed.). São Paulo: Atlas.

Miranda, A. C. M. (2014). Debate do plano diretor de Curitiba (Apresentação de slides) Curitiba: Câmara Municipal de Curitiba.

Nunes, N. T. R. (Coord.). (2012). Estudos de análise preliminar da viabilidade técnica para utilização das linhas férreas existentes na RMBH para o transporte ferroviário de passageiros (Relatório Técnico). Belo Horizonte: Universidade Federal de Minas Gerais.

Oliveira, L. H. (2005). Exemplo de cálculo de Ranking Médio para Likert. Varginha: PPGA CNEC/FACECA.

Silva, P. H. W. N. (2013). Mobilidade urbana de Porto Alegre/RS: a participação atual e o interesse pela adesão à mobilidade cicloviária (Trabalho de Conclusão de Curso). Universidade Federal do Rio Grande do Sul, Porto Alegre.

SDOT Blog. (2015). Seattle: Department of Transportation. Recuperado em 18 de março de 2015, de http://cossdotblog. wpengine.netdna-cdn.com/wp-content/uploads/2009/09/ sharrow12NE2.jpg

Vá de Bici. (2015). Porto Alegre. Recuperado em 18 de março de 2015, de https://vadebici.files.wordpress. com/2011/05/ciclofaixa.jpg

Recebido: Out. 06, 2015

Aprovado: Jul. 22, 2016 